\title{
INCIDENCIA DE FUSARIOSIS DE LA ESPIGA EN CULTIVARES DE TRIGO PAN DURANTE 2012-13 EN MARCOS JUÁREZ (CÓRDOBA-ARGENTINA)
}

\author{
Alberione, e. ${ }^{1 ;}$ Bainotti, C. ${ }^{1}$; Donaire, G. ${ }^{1} ;$ Fraschina, J. ${ }^{1}$; \\ Salines, J. ${ }^{1 ;}$ Salines, N. ${ }^{1} ;$ Gómez, D. ${ }^{1} ;$ CHulze, S. ${ }^{2} ;$ Palazzini, J. ${ }^{2} ;$ \\ MIR, L. ${ }^{1}$; FormicA, M. B. ${ }^{1} \&$ CUNIBERTI, M. ${ }^{1}$
}

\begin{abstract}
RESUMEN
En 2012 se caracterizaron cultivares de trigo frente a ataques severos de Fusariosis de la espiga en Marcos Juárez en ensayos de RET y bajo infección artificial. Se determinó incidencia, severidad rendimiento de granos, peso de mil granos (PMG), peso hectolítrico (PH), proporción de granos enfermos, contenido de deoxynivalenol (DON) y contenido de proteínas en granos, hallándose diferencias significativas $(\mathrm{p}<0,05)$. Se afectó el PH, PMG y rendimiento. Presentaron baja infección Lenox, LE 2330, ACA 356, Klein Zorro y Klein Tauro. El contenido de DON fue variable, no detectándose en Baguette 801Premium y SY200. Se observó inconsistente asociación entre infección y contenido de DON; fue baja en ACA 356 y LE 2330 y alta en ACA 906 y Klein León. La proteína no se vio afectada. La calidad industrial tuvo caídas en el W del alveograma. Los cultivares más destacados fueron Klein Zorro, Klein Tauro, Klein Proteo Cronox y SY200.

Palabras clave: Fusariosis, trigo, incidencia, DON, rendimiento.
\end{abstract}

\begin{abstract}
Fhb impact in bread wheat cultivars during 2012-13 in Marcos Juarez (Cordoba Argentina).

In 2012 was caracterized wheat cultivars against Fusarium head front FHB severes attacksin RET assays and under artificial infection conditions in Marcos Juárez. Was determined incidence, severity grain yield,thousand kernel weight (TKW), hectoliters weight (HW)damage kernels proportion deoxinivalenol content and protein content. In this variables was find significatives stadistic diferences $(\mathrm{p}<0,05)$. The HW, TKW and grain yield was afected for the disease. Little infection
\end{abstract}

1.- EEA Inta Marcos Juárez. Email: alberione.enrique@inta.gob.ar

2.- Universidad Nacional de Río Cuarto

Manuscrito recibido el 27 de julio de 2015 y aceptado para su publicación el 5 de abril de 2016 . 
E. Alberione et al.

was observed in Lenox, LE 2330, ACA 356, Klein Zorro y Klein Tauro. The DON content was variable. In Baguette 801Premium y SY200 wasn`t detected. Wasn`t observed lineal relation between infection and DON content; was littel in ACA 356 and LE 2330 and was hight in ACA 906 and Klein León. The protein wasn`t afected. The industrial quality falled in the W alveogram's. The cultivars most prominented was Klein Zorro, Klein Tauro, Klein Proteo, Cronox and SY200.

Key words: FHB, wheat, incidence, DON, yield.

\section{INTRODUCCIÓN}

La Fusariosis de la espiga (Fusarium graminearum Schawabe) es una enfermedad de importancia mundial en trigo (Triticum aestivum L.) (13). Lluvias frecuentes y alta humedad relativa ambiente, coincidentes con floración e inicio de llenado de granos, favorece la infección y el desarrollo de la enfermedad $(11 ; 21 ; 29)$. En Argentina se registraron epifítias severas en los años 1967, 1977 y 1978 con pérdidas de rendimientos de 10 a 30\% estimadas en Marcos Juárez (Córdoba) y Oliveros (Santa Fe) (24). En 1993 causó pérdidas de rendimiento de grano de 24 a $50 \%$ en sur de Santa Fe y sureste de Córdoba (24). En 2000 y 2001 se registraron ataques severos siendo importantes en Entre Ríos y centro-este de Santa Fe (24). Recientemente en 2012 bajo condiciones ambientales muy favorables a la enfermedad, se observaron niveles epidémicos muy severos en el cuadrante NE de la región pampeana con incidencias de $100 \%$ en el centro-oeste de Entre Ríos, centro de Santa Fe y NE de Buenos Aires (25). Bajo condiciones de infección artificial es razonable esperar mayores niveles de infección y también mayores contenidos de micotoxinas en granos (15). Entre sus efectos directos se cuenta la reducción del rendimiento en granos con una marcada des- mejora de la calidad comercial e industrial, dadas por la reducción del peso hectolítrico (kg/hl) y la contaminación con micotoxinas en granos y sus subproductos. La micotoxina más común es el deoxynivalenol (DON) aunque existen otros metabolitos (13; 14). En general se observa alta correlación entre el porcentaje de granos enfermos y la acumulación de DON (19). Por otra parte existe relación directa entre la severidad y el contenido de DON; a baja severidad menor contenido de DON (6). Las diferencias genotípicas de resistencia se manifiestan por niveles variables de la enfermedad en la espiga (19; 33), por la magnitud de la infección a nivel de granos (6) y por el contenido de DON (14). Finalmente todo esto incide sobre el rendimiento de granos $(1 ; 14)$ pudiendo verse directamente afectada también la comercialización, procesamiento industrial y la sanidad de los alimentos (1; $7 ; 8 ; 17 ; 32)$. La presencia de este patógeno y sus metabolitos afectan la calidad comercial y panadera (7; 8; 26 y 32). Se ve así finalmente afectada las propiedades de panificación por una menor calidad de las proteínas y menor fuerza de gluten $(1 ; 7$; 8). Con el objetivo de caracterizar el comportamiento de cultivares de trigo pan frente a Fusariosis de la espiga del trigo (FET) se realizaron evaluaciones sobre cuatro ensayos de la Red Nacional de Evaluación 